\title{
Astroenzymology - the environmental limits of enzyme activity
}

\author{
Roy M. Daniel \\ Department of Biological Sciences, University of Waikato, Hamilton, New Zealand.
}

\begin{abstract}
Using organisms from extreme terrestrial environments as models for extraterrestrial life may lead us to underestimate the range of environments that life may inhabit. An alternative approach is to inspect the range of conditions over which crucial biomolecules might function. Recent investigations of enzyme activity suggest that they have the potential to function over a wider range of environmental conditions than expected. Although the upper temperature limit for enzyme stability is unclear, some enzymes are active up to $130^{\circ} \mathrm{C}$. The evidence is that that the instability of enzymes is a functional requirement, rather than because of any restraint on achieving higher stability. There is no evidence that enzyme activity ceases at low temperatures; it declines in a predictable manner to the lowest temperature at which it has been possible to make measurements, $-100^{\circ} \mathrm{C}$. It has been generally accepted that dehydration stops enzyme activity but this acceptance may have arisen partly from the technical difficulty of assessing enzyme activity without a fluid medium for diffusion. Experiments using anhydrous organic solvents or gas phase substrates suggest activity occurs in enzymes at very low hydration.
\end{abstract}

Key words: hydration, temperature, protein stability, cryoenzymology

\section{INTRODUCTION}

Using organisms from extreme terrestrial environments as models of extraterrestrial life may lead us to underestimate the range of environments that life may inhabit. An alternative approach is to inspect the range of conditions over which biomolecules may be expected to function. Since virtually all cell functions depend on enzyme action, we consider here the properties of enzymes that might limit their functions under extreme conditions

The current general paradigm relating enzyme dynamics to activity suggests that enzymes need to be sufficiently flexible to be catalytically active, but not so flexible that they readily denature ${ }^{1-3}$. This explains why enzymes tend to denature 20?C above their "design" temperature. Too much stability would mean not enough flexibility for effective catalysis, too little stability means too short a useful lifetime. As we might expect from this flexibility/stability/activity relationship, although at room temperature "thermophilic" enzymes have been shown to be more rigid than their counterpart mesophilic enzymes, their flexibility (and specific activity, and half-life) is similar when each is at their "evolved" temperature ${ }^{2}$. So although it was once supposed that the upper temperature limit for life might be determined by the upper stability limits of enzymes, the evidence now is that the exact reverse is the case. The maximum temperature for life is about 110 ? C, and for enzyme stability about $130^{\circ} \mathrm{C}^{2}$. We do not find enzymes stable at 150 ? $\mathrm{C}$, for example, because their rigidity would impair their activity at $110^{\circ} \mathrm{C}$. For more stable natural enzymes we need organisms growing at higher temperatures, not vice versa.

At the other end of the temperature range, it has been suggested that enzyme function must cease at the dynamic transition of proteins ${ }^{4-5}$, which occurs at about $-50^{\circ} \mathrm{C}$; but enzyme activity has been measured over the years at succesively lower temperatures: So far down to-100C, with no obvious lower $\operatorname{limit}^{6}$.

A more serious restriction might seem to be enzyme hydration. It is generally accepted that protein hydration is essential for enzyme catalysis to occur, and that dry enzymes are inactive. Although there are varying estimates of the degree of hydration required for activity, a threshold value of about $0.2 \mathrm{~g} \mathrm{H}_{2}{\mathrm{O} . \mathrm{g}^{-1}}_{\text {protein is generally accepted }}{ }^{7-9}$. This is the level of hydration hat will be achieved by a protein in at atmosphere of a relative humidity of about $80 \%$. However evidence is accumulating that enzyme activity occurs at much lower hydration levels, and that the higher estimates may have arisen partly from the technical difficulty of assessing enzyme activity without a fluid medium for diffusion. 


\section{HIGH-TEMPERATURE STABILITY/ACTIVITY}

A variety of enzymes are known that have significant half lives at $>100^{\circ} \mathrm{C}$ (Table 1). Several structural studies have compared such proteins to much less stable variants from mesophiles ${ }^{11-13}$. Considering these results as a whole, the most significant finding is that although there are structural differences between very stable and "normal" enzymes, there is no pattern of systematic structural differences. Within a closely related group of enzymes there is evidence for a pattern of small differences between the more and less stable variants, but for a different group of enzymes the changes will be different: Overall, in structural terms the differences between very stable and less stable enzymes are no greater than the differences within the groups, and it is evident that structural changes are not a requirement for changed stability. This finding is entirely in keeping with early theoretical studies indicating that the tertiary structures of proteins are only marginally stable. [see ref 2]. Point mutational studies have shown that replacement of a single amino acid (and thus apparent removal of a single stabilizing interaction) can have a significant effect on stability without any detectable effect on the three-dimensional structure ${ }^{14}$. There is no evidence that in any protein all the amino acid residues are participating in stabilizing interactions. Because of this, and because each additional interaction can have such a marked stabilizing effect, it is difficult to determine what might be the upper limit for conformational stability. The temperature dependence of hydrophobic interactions suggests that these may be weak at $140^{\circ} \mathrm{C}[\mathrm{N}]$, so that this might seem to set an upper limit: But the hydrophobic interaction and the magnitude of its contribution to protein stability is incompletely understood $^{9,15}$. Since stability also depends on other interactions, as well as on any factors that may destabilize the unfolded state, then even if hydrophobic interactions are much weaker above $140^{\circ} \mathrm{C}$ this may not represent an upper temperature limit for protein stability.

There is strong evidence for, in general terms, an inverse correlation of conformational stability with specific activity, via molecular flexibility ${ }^{1-3}$. While enzyme activity is dependent upon flexibility, a less flexible enzyme will be more stable. The broadest general evidence for this is the finding that, at any given temperature, as a group enzymes from thermophiles are more stable, less flexible, and less active than those from mesophiles. Together with the general structural and functional identity of stable and less stable enzymes, this leads to the view that the instability of enzymes from mesophiles is a functional requirement, rather than because of any restraint on achieving higher stability. It is required so that enzymes have sufficient flexibility to perform their catalytic functions: i.e., enzymes tend to be denatured at temperatures not very far above their evolved or 'design' temperature because too much stability would mean not enough flexibility for effective catalysis, whereas too little stability would mean too short a useful lifetime ${ }^{2}$. An additional requirement for instability can be inferred from the finding that, irrespective of whether or not they are denatured, stable proteins are more resistant to proteolysis ${ }^{16}$. A balance between stabilizing and destabilizing interactions is required to meet the conflicting demands of stability on the one hand, and catalytic function and cellular turnover on the other. As a consequence, if we consider only conformational stability, we may postulate that the reason we have not found proteins that are stable much above $130^{\circ} \mathrm{C}$ is because we have not found organisms growing much above $110^{\circ} \mathrm{C}$ (rather than vice versa).

This general paradigm relating enzyme activity to stability via dynamics, nicely explains many observations. But we must bear in mind that the dynamics involved in activity is global, while that involved in activity may be local. Proteins exhibit a variety of internal motions, that cover a wide range of amplitudes $(0.01$ to $100 \AA)$ and timescales $\left(10^{-15}\right.$ to $>1$ s). Which of these are essential for enzymatic activity, and how these motions couple to each other, is not yet known. While it is evident that many of the motions involved in enzyme flexibility must occur over significantly shorter timescales than those of the enzyme rate-limiting step, the nature of the dynamic changes required for catalysis are unclear: for example, whether they are local or global, fast or slow ${ }^{17,18}$.

Although conformational stability can be maintained at high temperatures, irreversible degradative processes can lead to enzyme inactivation ${ }^{19}$. In contrast to denaturation, the irreversible processes of protein inactivation arise from changes in covalent bonding. Deamidation of the amide side chain of asn and gln, and succinimide formation are the most common amino acid degradations. These reactions have high activation energies and are thus greatly accelerated by high temperatures, and so have the potential to play a particularly important role in the inactivation of enzymes at high temperatures. 
However, the mechanisms and rate of degradation vary dramatically in different enzymes since they are mediated by protein structure and can be highly dependent upon local flexibility and neighboring amino acid residues. A survey of environments around Asp and Asn resides in known three-dimensional protein structures suggests that the rigidity of the folded protein greatly decreases the intramolecular imide formation necessary for degradation. At $37^{\circ} \mathrm{C}$ the rate of deamidation has been shown to be higher for small peptides, which have high flexibility, than for proteins when comparing the same amino acid sequence $\mathrm{e}^{20}$, and higher in denatured than in native proteins $\mathrm{s}^{21}$. In other words, there is evidence that the resistance to degradation of a protein is linked to its conformational integrity and that the degradative reactions to which proteins are subject are slower or do not occur in conformationally intact proteins, at least up to $100^{\circ} \mathrm{C}$. In other words, the upper temperature limit for protein stability may be determined by the conformational integrity of the protein. Although few studies on conformational or degradative stability above $100^{\circ} \mathrm{C}$ have been made, they support these findings 2,22 .

\section{LOW-TEMPERATURE ACTIVITY/STABILITY}

Since enzyme activity cannot be observed in the absence of a medium for the diffusion of substrate and product in and out of the active site, activity in aqueous solutions is not observed below their freezing points. However, cryoenzymology, which uses cryosolvents to enable the detection of activity at lower temperatures, is a well established field of enzymology ${ }^{23-25}$. The lowest temperatue at which enzyme activity has been measured to date is $-100^{\circ} \mathrm{C}^{6}$.

Activity at these temperatures is several orders of magnitude lower that at physiological temperatures. For the detection of enzyme activity at the lowest temperatures, assay reactions therefore involve long incubations and relatively high enzyme concentrations. The general procedure involves mixing enzyme and substrate below the desired reaction temperature, heating to the reaction temperature, then finally stopping the reaction with an agent such as sodium hydroxide in methanol. After slow warming to room temperature, end products can be measured. Control experiments are crucial to ensure that the activity measured was enzymic, and that any change in activity with temperature was not due to denaturation, substrate limitation, to $\mathrm{pH}$ effects, or failure to stop the reaction completely.

In the examples described below, full activity of the enzymes could be recovered after incubation in the cryosolvents at the temperatures used. Neither of the enzymes studied showed any evidence for cold denaturation. This is perhaps surprising given the very low temperatures and that the cryosolvents might be expected to have a tendency to denature the enzymes, but the results are consistent with those found for a variety of other enzymes studied well below $0^{\circ} \mathrm{C}^{24-26}$.

There are two factors causing reduced activity at low temperatures. Temperature itself has an effect, and the extent of this effect is governed by the Arrhenius activation energy (Ea). Most cryosolvents raise the Arrhenius activation energy and hence the rate at which activity decreases as the tenperature is lowered. This may be due to effects of solvent on the enzyme structure, or on the reaction catalysed ${ }^{27,28}$. The Arrhenius activation energy (Ea) for catalase was $15 \mathrm{~kJ} / \mathrm{mol}$ in buffer, 48kJ/mol in DMSO/ethylene glycol and $60 \mathrm{~kJ} / \mathrm{mol}$ in methanol/ethylene glycol ${ }^{6}$. Table 2 shows the extent of these effects.

Alkaline Phosphatase activity has been measured to $-100^{\circ} \mathrm{C}$, using methanol:ethylene glycol:water (70:10:20) as the cryosolvent (Fig. 1). Due to the slow enzymatic rates at low temperatures these points show some scatter, but there is no evidence for any significant deviation from linearity of the Arrhenius plot and a line of best fit gives an Arrhenius activation energy of $55 \mathrm{kJmoI}^{1}$, compared with $41 \mathrm{kJmol}^{-1}$, in aqueous solution ${ }^{6}$.

There is no evidence for any intrinsic lower temperature limit for enzyme activity. We do not know whether there is a lower temperature limit for enzyme activity above absolute zero. It is possible that an extrinsic limiting factor will be the necessity for a fluid medium to allow substrate and product diffusion. 
We believe the work has implications for life at low temperatures. The use of cryosolvents has the combined effect of reducing enzyme activity and increasing the Arrhenius activation energy. The result has been enzyme activities at $-90^{\circ} \mathrm{C}$ which are between 5 and 7 orders of magnitude lower than at $20^{\circ} \mathrm{C}$. Thus the turnover rate for catalase of more than $10^{5}$ $\mathrm{sec}^{-1}$ at $20^{\circ} \mathrm{C}$ falls to $10 \mathrm{sec}^{-1}$ in DMSO/ethylene glycol at $-50^{\circ} \mathrm{C}$ and to $2.3 \mathrm{~min}^{-1}$ in methanol/ethylene glycol at $-90^{\circ} \mathrm{C}$ (Table 2). But in a fluid medium that did not increase the Arrhenius activation energy or slow the reaction, the rate of reaction for catalase would fall less than 200 -fold from $+20^{\circ} \mathrm{C}$ to $-100^{\circ} \mathrm{C}$. However for alkaline phosphatase (and most other enzymes) the Arrhenius activation energy is higher than for catalase, so that at $40 \mathrm{~kJ} / \mathrm{mol}$ the rate of reaction will decease from that at room temperature by more than $10^{4}$ fold at $-90^{\circ} \mathrm{C}$. Nevertheless, in the presence of a suitable fluid, there seems no obvious reason to regard cessation of enzyme activity as a factor limiting the emergence or survival of life at very low temperatures.

\section{ENZYME HYDRATION}

It is generally accepted water is necessary for life, and specifically that protein hydration is essential for enzyme catalysis to occur; i.e., that dry enzymes are inactive. Although there are varying estimates of the degree of hydration required for activity, a threshold value of about $0.2 \mathrm{~g} \mathrm{H}_{2} \mathrm{O} . \mathrm{g}^{-1}$ protein, i.e. $0.2 \mathrm{~h}$, is generally accepted ${ }^{7-9}$. However, one difficulty with measuring activity in enzyme powders of low hydration is the absence of a medium for the diffusion of substrate and product. The approach involving the rapid mixing and freeze drying of enzyme and substrate solutions, for example, is likely to lead to measurements of product release rather than catalysis, and if enzyme cofactors such as NAD are involved the rates may be limited by the local availability of these rather than the hydration state of the enzyme. There is good evidence from work on enzyme catalysis in dry organic solvents that activity may be possible at very low hydrations ${ }^{29,30}$, but interpretation of this work is complicated by the likelihood that the organic solvent is replacing water at sites on the enzyme, as well as performing a hydration function by loosening the structure ${ }^{31,32}$. However, hydrogenase activity has been observed in the dry state ${ }^{33}$, and we have observed enzyme activity in milk powders at $<0.06 h^{34}$.

To date, studies using enzyme catalysis of gas phase substrates have had a biotechnological focus [15-20] but the obviation of any need for a diffusion medium for substrate and product gives the technique important potential in determining the hydration limits within which enzyme activity is possible. We have examined the effect of hydration on enzyme catalysis, in the absence of any requirement for water as a diffusion medium, by using vapour phase substrates. This approach also avoids the complication found in organic solvent work that the solvent may be affecting protein structure and hydration.

If enzyme catalysis is possible at appreciably lower hydration levels than $0.2 h$ (and in the absence of organic solvents), this will have significant implications for our understanding of the role of water in enzyme catalysis and protein structure. The onset of enzyme catalysis at the accepted value of $\sim 0.2 h$, corresponding in lysozyme to a water:enzyme mole ratio of $\sim 160$ and a surface coverage of 40-45\% [21, 22], coincides with (1) a greater conformational freedom in the water arrangements on the protein surface; (2) a transition at $\sim 0.25 h$ that is associated with the covering of the weakest interacting regions of the protein surface; and (3) the onset of intramolecular motions [1-5, 23-25]. Overall, hydration levels are thought to regulate the internal molecular motions that are necessary for catalysis, as well as acting as a diffusion medium.

Candida rugosa Lipase B and pig liver esterase were equilibrated to known hydration levels using atmospheres of specific RH (using saturated salt solutions), and the rate of hydrolysis of vapor phase ethyl butyrate investig ated. We found enzyme activity to be possible at much lower hydrations than expected [Lind, Dunn, and Daniel, unpublished results].

Apart from the obvious implications for life under restricted hydration, it should be noted that the results suggest that the minimum size requirement for cells may be less than has been thought. 


\section{REFERENCES}

1. R. Jaenicke, "Protein stability and molecular adaption to extreme conditions," Eur.J.Biochem. 202, pp. 715-728, 1991.

2. R. M. Daniel, M. Dines, and H. H. Petach, "The denaturation and degradation of stable enzymes at high temperatures," Biochem. J. 317, pp. 1-11, 1996.

3. R. M. Daniel, J. Bragger, and H. W. Morgan, "Enzymes from extreme environments," Biocatalysis, pp. 243-254, Abramowicz D.A.(ed), Van Nostrand Reinhold, New York, 1990.

4. F. Parak, E. N. Frolov, A. A. Kononenko, R. L. Mossbauer, V. I. Goldonskii, and A. G. Rubin, "Evidence for a correlation between the photo induced electron transfer and dynamic properties of the chromatophore membranes from Rhodospirillum rubrum," FEBS Lett. 117, pp. 368-372, 1980.

5. B. F. Rassmussen, A. M. Stock, D. Ringe, and G. A. Petsko, "Crystalline ribonuclease A loses function below the dynamical transition at 220K," Nature; 357, pp. 523-424, 1992.

6. J. M. Bragger, R. V. Dunn, and R. M. Daniel, "Enzyme activity down to $-100^{\circ}$ C," Biochim Biophys acta, 1480, pp. 278-282, 2000

7. J. A. Rupley, E. Gratton, and G. Careri, "Water and globular proteins," TIBS, 8, pp. 18-22, 1983.

8. J. A. Rupley, and G. Careri, "Protein hydration and function,” Adv. Prot. Chem., 41, pp. 37-172, 1991.

9. J. L. Finney, "Hydration processes in biological and macromolecular systems," Faraday Discuss., 103, pp. 1-18, 1996.

10. R. M. Daniel, and D. A. C. Cowan, "Biomolecular stability and life at high temperatures," Cell. Mol. Life Sci, 57, pp. 250-264, 2000.

11. P. R. Blake, J. B. Park, F. O. Bryant, S. Aono, J. K. Magnuson, E. Eccleston, J. B. Howard, M. F. Summers, and M. W. W. Adams, "Determinants of protein hyperthermostability. 1. Purification, amino acid sequence, and secondary structure from NMR of the rubredoxin from the hyperthermophilic archaebacterium," Pyrococcus furiosus. Biochemistry, 30, pp. 10885-10891, 1991.

12. G. Auerbach, R. Ostendorp, L. Prade, I. Korndorfer, T. Dams, R. Huber, and R. Jaenicke, "Lactate dehydrogenase from the hyperthermophilic bacterium Thermotoga maritima," Structure, 6, pp. 769-781, 1998.

13. R. J. M. Russell, U. Gerike, M. J. Danson, D. W. Hough, and G. L. Taylor, "Structural adaptation of the cold active citrate synthase from an Antarctic bacterium," Structure, 6, pp. 351-361, 1998.

14. M. G. Grutter, R. B. Hawkes, and B. W. Matthews, "Molecular basis of thermostability in the lysozyme from bacteriophage T4," Nature, 277, pp. 667-669, 1979.

15. T. E. Creighton, Proteins, $2^{\text {nd }}$ edn, W.H.Freeman, New York, 1993.

16. R. M. Daniel, D. A. Cowan, H. W. Morgan, and M. P. Curran, “A correlation between protein thermostability and resistance to proteolysis," Biochem. J., 207, pp. 641-644, 1982.

17. R. M. Daniel, J. C. Smith, M. Ferrand, S. Hery, R. Dunn, and J. L. Finney, "Enzyme activity below the dynamical transition at 220K," Biophys J., 75, pp. 2504-2507, 1998.

18. R. V. Dunn, V. Reat, J. L. Finney, M. Ferrand, J. C. Smith, and R. M. Daniel, "Enzyme activity and dynamics: Xylanase activity in the absence of fast anharmonic dynamics," Biochem. J., 346, pp. 355-358, 2000. 
19. T. J. Ahern, and A. M. Klibanov, "The mechanism of irreversible enzyme inactivation at $100^{\circ} \mathrm{C}, "$ Science, 228 , pp. 1280-1283, 1985.

20. T. V. Brennan, J. W. Anderson, Z. Jua, E. B. Waygood, and S. Clarke, "Repair of spontaneously deamidated HPR phosphocarrier protein catalysed by the L-isoaspartate -(D-aspartate) O-methyltransferase," J. Biol. Chem., 269, pp. 24,586-24,595, 1994.

21. S. J. Wearne, and T. E. Creighton, "Effect of protein conformation on rate of deamidation: Ribonuclease A," Proteins Struct. Funct. Genet., 5, pp. 8-12, 1989.

22. R. Hensel, I. Jakob, H. Scheer, and R. Lottspeich, "Proteins from hyperthermophilic archaea: stability towards covalent modification of the polypeptide chain," Biochem. Soc. Symp., 58, pp.127-133, 1992.

23. P. Douzou, "The use of subzero temperatures in biochemistry: slow reactions," Methods Biochem. Anal., 22, pp. 401-512, 1974.

24. P. Douzou, "Enzymology at subzero temperatures," Adv. Enzymol., 45, pp. 157-272, 1977.

25. A. L. Fink, and M. A. Geeves, "Cryoenzymology: The study of enzyme catalysis at subzero temperatures," Methods Enzymol., 63, pp. 336-370, 1979.

26. N. More, R. M. Daniel, and H. H. Petach, "The effect of low temperatures on enzyme activity," Biochem. J., 305, pp. 17-20, 1995.

27. P. D. Compton, R. J. Coll, and A. L. Fink, J. Biol. Chem., 261, pp. 1248-1252, 1986.

28. F. Travers, and T. Barman, Biochimie, 77, pp. 937-948, 1995.

29. R. H. Valivety, P. J. Halling, and A. R. Macrae, "Rhizomucor miehei lipase remains highly active at water activity below 0.0001,” FEBS Lett., 301, pp. 258-260, 1992.

30. A. M. Klibanov, "Enzymatic catalysis in anhydrous organic solvents," TIBS, 14, pp. 141-144, 1989.

31 R. Affleck, Z-F. Xu, V. Suzawa, K. Focht, and D. S. Clark, "Enzymatic catalysis and dynamics in low-water environments," Proc. Natl. Acad. Sci. USA, 89, pp. 1100-1104, 1992.

32. J. Wu, and D. G. Gorenstein, "Structure and dynamics of cytochrome c in nonaqueous solvents by 2D NHexchange NMR spectroscopy,” J. Am. Chem. Soc., 115, pp. 6843-6850, 1993.

33. T. Yagi, M. Tsuda, Y. Mori, and H. Inokuchi, "Hydrogenase activity in the dry state," J. Am. Chem. Soc., 91, p $2801,1969$.

34. L. Chen, Thermophilic Enzymes and Their Impact on Milk Powders During Storage, Ph.D Thesis, University of Waikato, Hamilton, New Zealand, 2001.

35. S. Pulvin, M. D. Legoy, R. Lortie, M. Pensa, and D. Thomas, "Enzyme technology and gas phase catalysis: Alcohol dehydrogenase example,” Biotechnol. Lett., 8, pp. 783-784, 1986.

36. K. Barzana, A. M. Klibanov, and M. Karel, "Enzyme-catalysed gas phase reactions," Appl. Biochem. Biotechnol., 15, pp. 25-33, 1987.

37. S. Lamare, and M. D. Legoy, "Working at controlled water activity in a continuous process: the gas/solid system as a solution," Biotechnol. Bioeng., 45, pp. 387-397, 1995. 
Figure legend

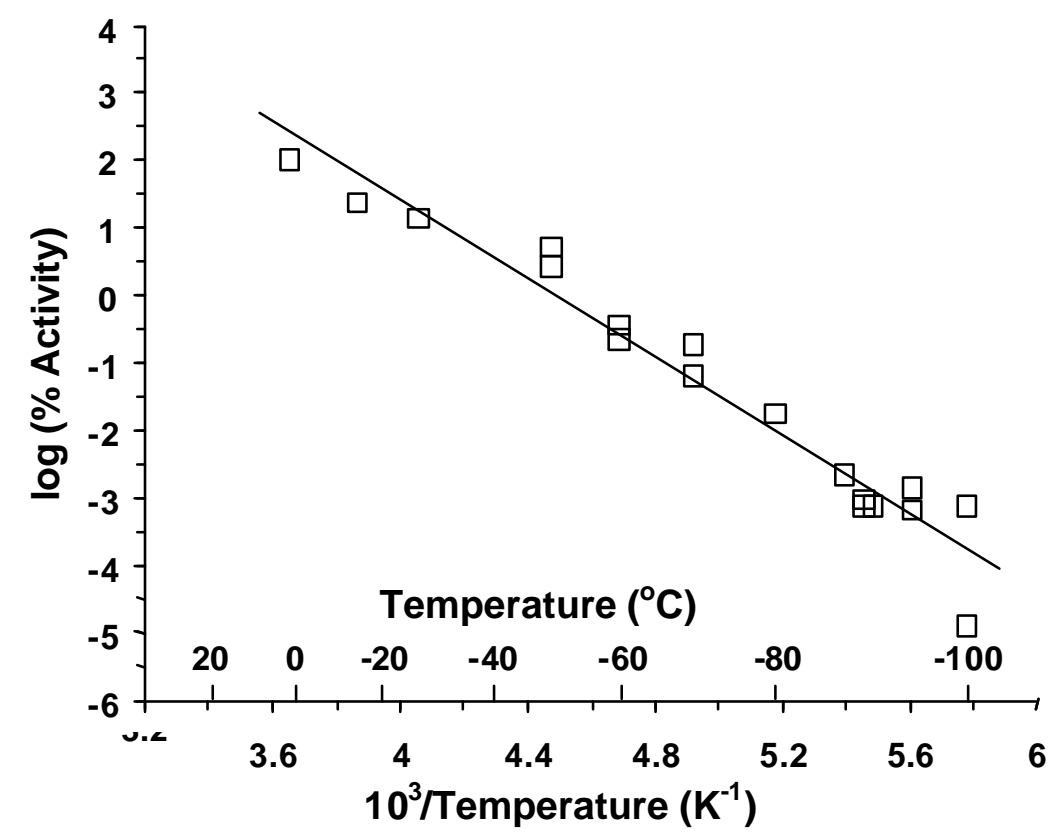

Figure 1: Arrhenius plot of alkaline phosphatase

Effect of temperature on the activity of alkaline phosphatase in methanol/ethylene glycol/water (70/10/20) [Data from ref 6] 


\begin{tabular}{|l|l|}
\hline Enzyme (Source) & $\mathbf{T} \mathbf{1} \mathbf{2}_{\mathbf{2}}$ at $\mathbf{1 0 0}^{\circ} \mathbf{C}$ \\
\hline Cellobiohydrolase (Thermotoga) & $>200 \mathrm{~min}$ \\
?-Glucosidase (Thermotoga) & $90 \mathrm{~min}$ \\
Xylosidase (Thermotoga) & $150 \mathrm{~min}$ \\
Esterase (Sulfolobus) & $60 \mathrm{~min}$ \\
Hydrogenase (Pyrococcus) & $120 \mathrm{~min}$ \\
Amylase (Pyrococcus) & $360 \mathrm{~min}$ \\
DNA-dependent RNA polymerase (Thermoproteus) & $>120 \mathrm{~min}$ \\
\hline
\end{tabular}

Table 1: Stability of some enzymes at $100^{\circ} \mathrm{C}$

$\mathrm{T}_{1 / 2}$ values are half-lives of activity under specified, but not identical, conditions of $\mathrm{pH}$ etc. [Data from ref 10] 
Solvent

$10 \mathrm{mM}$ phosphate buffer, $\mathrm{pH}_{20} 6.5$

$60 \%$ DMSO/20\% ethylene glycol

$70 \%$ Methanol/10\% ethylene glycol

50

$-90$

$-97$
Turnover number $\sec ^{-1}$

$1.9 \times 10^{5}$

$7 \times 10^{4}$

1916

447

10

2.5

0.038

0.0032

Table 2: Turnover numbers of catalase in cryosolvents [data from ref 6] 